septum, give rise to a dull ache with exacerbations at the menses, and if provoked by intercourse or the passage of a bulky motion. Carcinoma of the uterus does not cause backache in its early stages. Indeed the degree of pain can give some indication as to operability, for in the later stages it is usually very severe.

Several workers have investigated the incidence and causation of gynaecological backache, and of these Lynch's results may be taken as representative. In a series of I,04I cases $49 \%$ complained of backache, and of these, in a one to eight year follow-up, $76.5 \%$ were relieved of their pain by operation. His results may be summarised as follows:-

\begin{tabular}{|c|c|c|c|c|c|}
\hline $\begin{array}{l}\text { No. of } \\
\text { cases }\end{array}$ & Pathology & & & $\begin{array}{l}\text { Percentages } \\
\text { with backache }\end{array}$ & $\begin{array}{l}\text { Percentag } \\
\text { ache cured }\end{array}$ \\
\hline 28 & Ovarian tumours & .. & .. & $\ldots \quad I 5 \cdot 4$ & \\
\hline IOI & Fibroids $\quad \ldots$ & . & .. & 34 & \\
\hline 434 & Pelvic inflamation ... & . & .. & 49 & \\
\hline 290 & Retroversion and flexion & $\ldots$ & .. & $6 I$ & \\
\hline 125 & Marked vaginal relaxation & .. & .. & $7 I$ & \\
\hline 63 & Complete prolapse .. & .. & .. & 22 & \\
\hline
\end{tabular}

Treatment.-As indicated by the above table, operation offers the best chance of cure, but palliative treatment is often of great value and should always be tried first. For instance, an extended course of pelvic heat by hot douching or diathermy will considerably improve most cases of pelvic inflammation. The retroverted uterus may often be put forward and held by a pessary, when, the congestive effect of the twisting of the broad ligament being removed, the organ has a better chance to settle down to a normal state. Vaginal laxity and early prolapse can be controlled by a ring pessary as a rule, but unless there are contra-indications, such as an active child-bearing age or some cardiac or other reason, operation in these cases should always be advised, for a ring pessary is not a cure, and only slows down the prolapsing process.

1. ADAMS, Amer. Jour. Obs. Gyn., 1927, 14, 742.

REFERENCES

2. SOMERVILLE \& ROSS, Further Experiences of an Irish R.M.

3. MCKANE, New Zealand Med. Jour., I933, 32, 62.

4. LYNCH, F. W., Amer. Jour. Obs. Gyn., 1926, $12,19$.

\title{
VITAMINS AND MILK STANDARDS
}

We have been asked to publish the two following reports, issued by the British Paediatric Association, in order to lay before the profession, in the briefest possible way, the results obtained, following careful investigations on the two questions of Vitamin D and milk supplies. These results have a most important bearing upon the health of the rising generation, to whom we look to take up the struggle after "the sweat, the toil, the tears and the blood" of this present war are past. They, the rising generation, must be given the opportunity of sustaining this great heritage of ours for which we now fight. To do that, they must be blessed with a healthy mind and body.

The recommendations laid down in these reports are, therefore, worthy of close attention, because the prevention of illness in early years is surely a most valuable contribution to the future health of our young population.

\section{REPORT ON THE INVESTIGATION INTO THE STANDARD OF MILK SUPPLIED TO CHILDREN}

\section{Conclusion of the Survey.}

(Dr. A. G. Watkins, Cardiff.)

I. There is no available evidence of an increase in milk-borne diseases since the outbreak of the war. The shifting population makes accurate statistical figures difficult to obtain, though in some areas there is formed a clinical impression of an increase in tuberculosis of the glands of the neck.

2. There is a definite lowering of the bacteriological quality of milk as supplied since the outbreak of war.

3. Frequent comments are made by Medical Officers of Health, concerning the unsatisfactory pasteurisation of milk at the present day. 
4. There is likely to be a decrease in the standard of milk, especially in its keeping qualities, due to war-time transport problems.

\section{Recommendations Suggested.}

I. All pooled milk (other than "reject" and "Salvage" C.M.D. 6362) must be efficiently pasteurised. Increased inspection of cooling facilities on farms and of pasteurisation technique should be performed.

2. Until all milk is efficiently pasteurised, the public should be instructed to scald all liquid milk for children up to at least five years of age; for preference dried milk should be used for all infants.

3. These investigations reveal that the safeguards taken to ensure that pasteurisation is efficient are not reliable, and it is recommended that steps be taken to remedy this state of affairs.

\section{REPORT OF INVESTIGATION ON THE ADEQUATE DOSAGE OF VITAMIN D FOR CHILDREN \\ (Drs. Wilfred Sheldon, Noah Morris, Helen Mackay (co-opted) and Charles Harris.)}

I. Opinions on Vitamin $\mathrm{D}$ requirements of infants and children, expressed in international units.

(a) The minimum requirement for infants and children is not known.

(b) The Technical Commission on Nutrition of the League of Nations (I938) place the requirements of infants at $400-500$ i.u. daily.

(c) The Committee of Food and Nutrition of the National Research Council in the U.S.A. and the Committee on Vitamins of the American Academy of Paediatrics (Dann and Davison, I942) put the requirements of children from birth up to 15 years of age at 400-800 i.u. daily.

(d) The figure in $(c)$ has been endorsed by the National Nutrition Conference for Defence (I94I) summoned by President Roosevelt.

(e) Park and Eliot (I942) consider that 800-I,000 i.u. daily cover all possible requirements of full-term infants.

$(f)$ During the last ten years it has been the practice at St. Bartholomew's Hospital, London, to give daily doses of 600 i.u. in the form of cod liver oil to all infants as a prophylactic measure.

(g) Premature infants (i.e. infants whose birth weight is below $5 \frac{1}{2} \mathrm{lb}$.), vary more widely in their individual requirements than do full-term infants, but their need is uniformly higher. Their daily routine allowance should be twice that of full-term infants, and should be continued at this rate until after their second birthday.

(h) The incidence of active rickets is as great under six months of age as over. In view of the more active growth rate in the earlier months of life, the prophylactic requirement of Vitamin $\mathrm{D}$ is greater during these months.

(i) Generally, in Great Britain during the summer months, sunshine and skyshine can be relied upon to protect full-term infants from rickets, provided they are suitably exposed to these elements for at least 4 hours daily. This provision cannot, however, be expected to be uniformly available, especially under the difficult conditions of wartime. During the winter months little Vitamin $\mathrm{D}$ is rendered available by natural irradiation. Therefore it is considered that seasonal variations in Vitamin $\mathrm{D}$ allowance would be unwise.

(j) With regard to children beyond the age of infancy, who are receiving a mixed diet, the amount of Vitamin D obtainable from their food is subject to much variation, and in any case is small, so that a reduction of the amount of Vitamin D supplement is considered to be unjustified.

(k) In regard to infants, this report does not distinguish between those who are breast fed and those artificially reared; it being considered that a supplementary ration of Vitamin D should be issued impartially to both groups of infants, irrespective of whether or not nursing mothers are to be allowed a Vitamin D supplement.

\section{The Present Official Dosage of "Cod Liver Oil Compound."}

The cod liver oil.compound supplied by the Government as a supplementary ration for children under 5 years of age, contains "not less than Ioo i.u. of Vitamin D per gramme." The maximum dosage for children under 6 months old is "half a teaspoonful daily" and for 
those over 6 months "one teaspoonful." On a generous interpretation, this provides 200 i.u. daily under 6 months of age, and 400 i.u. daily for older infants. It would be hard to find any authority, with clinical experience, to support so small a dose. Moreover, it will be noted that infants under 6 months are allowed a smaller dose than older babies, which does not accord with their actual needs.

\section{Recommendations re Dosage of Vitamin $D$.}

A daily allowance under the Government Scheme ought to be sufficient to protect practically all babies under the varying circumstances of their lives, without the necessity of having to obtain through private channels any additional Vitamin D.

(a) Full-term infants and children up to 5 years old.

Although a daily intake of $500 \mathrm{i}$.u. would probably protect the majority of full-term infants and young children, a daily allowance of 700 i.u. would give a wider margin of safety. For simplicity in administration, a "vitaminised" oil should be so reinforced with irradiated ergosterol that I fluid drachm would contain the daily allowance of 700 i.u.- as well as the 3,500 i.u. of Vitamin A now provided in each drachm.

(b) Premature infants (under $4 \frac{1}{2} \mathrm{lb}$ at birth) from birth to 2 years.

The allowance should be double that in paragraph $3(a)$, i.e. a daily allowance of 1,400 i.u. contained in 2 fluid drachms of "vitaminised" oil.

\section{(c) School Children.}

Information regarding the Vitamin D needs of school children is meagre, although there is much to suggest that Vitamin D deficiency is one factor in the aetiology of dental caries occurring in our school children. Also taking into consideration the small amount of fat, fish, eggs and meat fat that is available, it is recommended that a supplement of 3,500 i.u. of Vitamin D per week be allowed for this group of children. Administratively, this supplement might be issued with school milk, or through the medium of school dinners.

\section{(d) Pregnant and Nursing Women.}

It is recommended that a supplement of $700 \mathrm{i} . \mathrm{u}$. of Vitamin $\mathrm{D}$ daily should be allowed to this group of the community. The provision of such a supplement should not do away with the supplement for breast-fed infants.

\section{Suggestions Concerning the Routine Administration of Vitamin D.}

Printed directions for the mother should be issued with the ration of Vitamin D. These should include instructions-

(a) To start the oil gradually, beginning with a few drops daily when the infant is a month old, and taking a fortnight to work up to the full dose of one teaspoonful (70o i.u. daily).

(b) To inform her that for an infant whose weight at birth is over $5 \frac{1}{2}$ lb. the supplement of Vitamin $\mathrm{D}$ need not be given on summer days, provided the infant is out of doors during the morning and afternoon.

(c) To warn her that an infant whose birth weight is below $5 \frac{1}{2} \mathrm{lb}$. is particularly susceptible to rickets; that an allowance of Vitamin D supplement must therefore be doubled to 2 teaspoonfuls daily, and that this should be divided into 4 equal doses each day, and begun gradually; and that this supplement should be given throughout summer and winter; and that all premature babies should be under regular medical supervision.

For the information of doctors, the composition and Vitamin content of "cod liver oil compound" should be given on the label, and published in the Medical Press.

Thus it will be realised how far short we may fall in our advices by issuing rule-of-thumb instructions.

\section{REFERENCES}

(I) DANN, W. J., and DAVISON, W. C. (1942), Technical Commission on Nutrition, 1938, Bulletin of Health Organisation, League of Nations, $\mathbf{7}, 460 ;$ Amer. J. Dis. Child, LXIII, 366.

(2) National Nutrition Conference for Defence, r94I, Public Health Rep., XVI, 1233.

(3) ELIOT, M. M., and PARK, E. A. (1942), Practice of Paediatrics, edited by Brennemann, J., W. F. Prior, Hagerstown, Maryland, 1. 36,97 . 